\title{
OS JOGOS EDUCATIVOS ONLINE NO ENSINO DA DISCIPLINA DE LÍNGUA PORTUGUESA.
}

\author{
$\underline{\text { Monique Santos de Santana }}{ }^{1}$; Solange Mary Moreira Santos ${ }^{2}$; Helena Costa Matos ${ }^{3}$ \\ Maísa Lis Costa dos Santos ${ }^{4}$ \\ 1. Bolsista PIBIC/CNPq, Graduanda em Licenciatura em Pedagogia,Universidade Estadual de Feira de Santana, e-mail: \\ monisks@hotmail.com \\ 2. Orientadora, Departamento de Educação, Universidade Estadual de Feira de Santana, e-mail: \\ solangemmsantos@gmail.com \\ 3. Bolsista FAPESB, Graduanda em Licenciatura em Pedagogia, Universidade Estadual de Feira de Santana, e-mail: \\ helenamatosfsa@gmail.com \\ 4. Bolsista FAPESB, Graduanda em Licenciatura em Pedagogia, Universidade Estadual de Feira de Santana, e-mail: \\ maiisacliis@hotmail.com
}

PALAVRAS-CHAVE: TICs, Jogos educativos, Aprendizagem online; Educação inovadora.

\section{INTRODUÇÃO}

Na sociedade contemporânea, as Tecnologias de Informação e Comunicação (TICs) apresentam mudanças significativas em relação ao modo como desenvolvemos o nosso trabalho, como estabelecemos comunicação uns com os outros, como produzimos conhecimento, enfim como vivemos (CASTELL, 2003).

Nesse sentido, o desafio é a integração das TICs no processo de ensino-aprendizagem, tendo em vista a possibilidade de mudanças no acesso aos saberes, permitindo aos alunos construírem novos modelos e formas de agir na sociedade. Para isso, as atividades desenvolvidas em sala de aula precisam ser mediadas pelo professor, porque os alunos dessa nova geração, por mais que sejam considerados nativos digitais precisam estar preparados para atuar na cultura da informação e do conhecimento.

A esse respeito, Carbonell (2002) declara que os sintomas de mudança precisam estar presentes no espaço escolar, fazendo com que os artefatos tecnológicos cumpram uma função diferenciada em relação aos livros que se limitam a ditar as lições de sempre. As TICs são vistas no âmbito da escola, como recurso que pode contribuir para a mudança na prática docente, assim como na atividade curricular dos seus alunos, tendo em vista que possibilitam o aprimoramento e a ampliação do conhecimento, tanto prático quanto técnico e científico. Então, é preciso que a utilização dessas ferramentas tecnológicas se concretize com práticas inovadoras, propiciando assim a aquisição de novos significados pedagógicos.

Desse modo, torna-se fundamental a preparação e a qualificação do professor para, usar as tecnologias da melhor maneira possível na sua prática docente, tendo em vista que o professor precisa se inserir nesse novo modelo, uma vez que, o processo ensino-aprendizagem precisa ser renovado para não cair na monotonia e tornar-se algo mecânico.

Assim, o uso dessas tecnologias serve tanto para inovar o ensino quanto contribui para elaboração de estratégias que facilitem a interação dos educandos em relação aos conteúdos curriculares, podendo ampliar o conhecimento e favorecer a utilização da comunicação e informação de modelos comunicativos de ensino (PORTO, 2006). Ao pensar nos inúmeros atrativos que as TICs proporcionam aos seus usuários, a perspectiva desta investigação é a de responder as seguintes questões: Quais as contribuições dos jogos digitais, como ferramenta pedagógica, para o desenvolvimento do processo de ensino-aprendizagem? E como eles estão sendo utilizados nesse processo? Para a compreensão de tal problema elencou-se como objetivo geral da pesquisa analisar como os jogos educativos "online" possibilitam aulas interativas no ensino da Língua Portuguesa. E como objetivos específicos: discutir o uso de jogos educativos 
online no ensino de Língua Portuguesa; identificar jogos educativos em sites para uso nas atividades de Língua Portuguesa.

Nesse sentido, essa investigação foi proposta na tentativa de compreender a possibilidade do universo lúdico da internet como mais um espaço de produção de sentido, que desenvolvem novas formas de conhecimento e de interação, perpassando os espaços concretos, ampliando o campo infinito de opções e de ludicidade do mundo digital. Assim, este trabalho visa averiguar o caráter pedagógico dos jogos digitais na perspectiva de contribuir para mudança na prática docente, bem como no processo de aprendizagem dos alunos.

\section{METODOLOGIA}

Para estabelecer um olhar investigativo sobre a utilização, os jogos educativos online no ensino da disciplina de língua portuguesa, esta pesquisa se fundamentou em uma abordagem qualitativa do tipo descritiva, a partir de estudos bibliográficos (dissertações, artigos, livros, dentre outros) que utilizam o jogo educativo digital no Ensino Fundamental, das publicações no Banco de Teses e Dissertações da Coordenação de Aperfeiçoamento de Pessoal de Nível Superior (CAPES), nos 2011 e 2012, bem como a construção e aplicação de oficina intitulada: "Exercitando a leitura e a escrita jogando". Essa oficina teve como proposta trabalhos com os jogos educativos online no Ensino Fundamental.

Segundo Oliveira (2007) a abordagem qualitativa funciona como "um processo de reflexão e análise da realidade através da utilização de métodos e técnicas para a compreensão detalhada do objeto de estudo em seu contexto histórico e/ou segundo sua estruturação".

Os sujeitos participantes desta oficina foram alunos do $4^{\circ}$ ano do Ensino Fundamental em uma escola pública, do Município de Feira de Santana- Ba. A escola escolhida para realização da oficina, tem em seu espaço educativo, uma sala de informática equipada com computadores e acesso a internet, no qual facilitou para realização do trabalho com os jogos educativos online no Ensino Fundamental, atividade proposta na oficina.

Foi utilizado como instrumento para a coleta de dados um questionário, no qual versou sobre os jogos online que os sujeitos partícipes acessam diariamente e se fazem uso deles no ambiente escolar. Esses procedimentos metodológicos proporcionaram a compreensão e busca de respostas à questão de pesquisa, favorecendo a discussão sobre a possibilidade de utilização dos jogos educativos online como recurso pedagógico.

\section{RESULTADOS}

A coleta de dados dos estudos e pesquisas realizadas no Baco de Teses da Capes, são referentes às publicações dos anos de 2011 e 2012, justamente por se tratar de um levantamento realizado antes da atualização da Plataforma Sucupira. Nesses anos só encontramos dissertações que tratam sobre o uso dos jogos online no Ensino Fundamental. Diante dessa problemática, decidimos nesse primeiro momento desta investigação permanecer com os estudos dissertativos selecionados na primeira coleta de dados. Contudo, vale ressaltar que recentemente foi realizado um novo levantamento, no Banco de Teses da CAPES, no período de março/2016 a junho/2016 na nova Plataforma Sucupira sobre as teses e as dissertações publicadas nos anos de 2013 a 2016. Encontramos nesses anos um número considerável de estudos que tratem sobre a utilização de jogos educativos online na prática educativa.

No decorrer desta investigação, percebemos que as propostas de estudos estão diversificadas, alguns dos estudos evidenciam a prática realizada com o jogo e os resultados conquistados, outros apresentam os fundamentos teóricos e também outros que falam sobre a criação de jogos que podem ser utilizados na Educação. 
Fizemos a leitura de 22 resumos que indicaram a utilização dos jogos online no ensino e aprendizagem. Dessas análises, realizamos uma leitura na íntegra e selecionamos 6 produções com a finalidade de fazer uma reflexão crítica sobre fundamentos teórico-metodológico relacionadas à temática.

Dentre as 6 (seis) dissertações selecionadas para análise aprofundada deste trabalho, 2 (duas) estão voltadas para área de Matemática, 1 (uma) na área de Ciências, 2 (duas) analisam a utilização dos jogos na educação de modo geral, sem especificar a área de conhecimento, abordando como a virtualização do lúdico implica na formação da criança. E 1 (uma) voltada para área de Língua Portuguesa. Todavia, com base na leitura desses estudos podemos considerar que os demais componentes curriculares, trabalham a Língua Portuguesa de forma interdisciplinar, uma vez que possibilitam aos alunos a prática da interpretação, e do desenvolvimento da linguagem para resolução das situações-problemas propostas na aprendizagem. Desse modo, passamos a discutir o que tratou cada dissertação presente no quadro acima.

Durante a realização das atividades pertinentes a oficina, os alunos apontaram suas experiências com os jogos, os métodos de buscas pelos mesmos, os mais utilizados, indicações de jogos e instruções de como se joga esses games. Vale ressaltar que, diante dessa interação com os alunos, foi estabelecido trocas de experiências, que tornou o ambiente enriquecedor e produtor de conhecimentos, partindo da concepção de que o sujeito se constrói a partir das interações com o meio e com os objetos. Nesse sentido, Silva (2007) assevera que,

\footnotetext{
O sujeito conhece na interação e não na recepção passiva submetida ao falar-ditar. Ele constrói o conhecimento à medida que estabelece trocas com o meio e com os objetos e isto confirma a prioridade da construção do conhecimento sobre a transmissão de informações. Assim, o conhecimento vem das interações e não da assimilação de enunciados. (SILVA, 2007, p. 177).
}

Fica evidente nesse estrato a necessidade do professor estar atento para essas possibilidades de comunicação entre professor-aluno, aluno-aluno, aluno-professor e favorecer a participação do aluno através do diálogo na construção do saber.

Dentro das informações colhidas através das falas dos alunos, foi possível perceber que os dispositivos eletrônicos que eles utilizam para jogar são celulares, tabletes, computadores e videogames, sendo que essas ferramentas também possibilitam a utilização de jogos online, no qual os seus usuários se comunicam através de salas virtuais em tempo real.

À medida que era estabelecido a comunicação com os alunos, mais contribuições acerca da utilização de jogos foram surgindo, principalmente ao esboçarem quais jogos que eles mais gostam de utilizar. A maioria dos alunos apontou que utiliza o jogo chamado Minecraft (jogo de construção), que pode ser jogado, também, através da rede social Facebook. Além do Minecraft houve outras opções significativas de jogos, tais como, GTA (jogo de luta) Slitherio (jogo de cobra), Tanki Online (jogo de batalha). Entretanto, dentre os relatos, e diante dos questionamentos sobre o uso de jogos educativos, um dos alunos presentes expressou a partir do seu comentário que já fez uso de um jogo educativo para estudar os números, e os demais disseram que o único contato foi na sala de informática, mas com pouca frequência, considerando que o ambiente escolar não tem professor de informática. Além disso, as práticas que foram relatadas nas atividades com jogos, os estudantes exprimiram que eram atividades de pintura.

A realização desta atividade possibilitou aos alunos trabalharem a observação na busca de criarem estratégias para resolver as situações-problemas além de descreverem quais métodos utilizaram a partir de suas análises.

Outro ponto relevante a ser destacado, está relacionado à formação do sujeito que faz uso das tecnologias no cotidiano. Mediante o contato estabelecido com alguns alunos da rede 
pública de ensino para a realização da oficina, foi possível perceber que, a maneira as quais utilizam os recursos tecnológicos ainda está fragmentada, considerando que não há uma seleção nas informações existentes nesse meio de comunicação e interação, que é a Internet.

No caso dos jogos online, que tem acesso direto com a internet, é interessante se pensar em uma reeducação para com as crianças e jovens a partir das aulas de informática, de modo que os alunos tenham mais conhecimento sobre a forma adequada para utilização desses recursos, tendo em vista que assim como a internet é um campo de informações e interações, essa rede de computadores também fornecem conteúdos impróprios e de pouco significado.

\section{CONCLUSÃO}

Durante o desenvolvimento da pesquisa, os estudos revelaram que o jogo online pode se tornar um mecanismo de inovação na prática pedagógica, por dinamizar a didática da sala de aula e possibilitar aos alunos uma aprendizagem consistente e prazerosa.

Nos estudos e na oficina, vimos que os jogos online, de modo geral, podem funcionar como ferramentas lúdicas e atrativas no processo de ensino e aprendizagem. Porém para que a utilização dos jogos possibilite a construção do conhecimento, o professor precisa averiguar a ludicidade presente nos jogos a serem utilizados e se os mesmos fazem parte do cotidiano dos alunos, uma vez que para criar a interação e o envolvimento dos sujeitos é viável que concilie a didática com os interesses dos alunos.

O uso de jogos, no processo ensino-aprendizagem pode desenvolver uma maior autonomia em relação às atividades curriculares, além de motivar o interesse e a participação dos alunos nesse processo educativo. Assim, intercalar os componentes curriculares do Ensino Fundamental aos jogos didáticos é enfatizar a grande importância que essas disciplinas representam, não só pelo fato de ser uma das etapas da educação básica, mas também por ser fase de transição de crianças e jovens para todas as áreas do conhecimento, tendo em vista que essa conexão pode contribuir para melhorar a qualidade desse nível de ensino.

Diante disso, podemos considerar o universo lúdico da internet como mais um espaço de produção de sentido, que desenvolvem novas formas de conhecimento e de interação, perpassando os espaços concretos, ampliando o campo infinito de opções e de ludicidade do mundo digital.

\section{REFERÊNCIAS}

CASTELLS, Manuel. A Galáxia da Internet: reflexões sobre a internet, os negócios e a sociedade. Tradução Maria Luiza X. de A. Borges. Rio de Janeiro: Zahar, 2003.

CARBONELL, Jaune. A aventura de inovar: a mudança na escola. Tradução. Fátima Murad. Porto Alegre: Artmed Editora, 2002.

OLIVEIRA, Maria M. Como fazer pesquisa qualitativa. Petrópolis, RJ: Vozes, 2007.

SILVA, Siony. Redes sociais digitais e educação. Revista Iluminart, n. 5, Ago.2010.Disponívelem:<http://www.cefetsp.br/edu/sertaozinho/revista/volumes_anteriores/ volume1 numero6/volumes_anteriores/volume1 numero5/ARTIGOS/volume1 numero5artigo4. pdf>. Acesso em: 16 jun. 2015. 